\title{
Reconstructive Habits: Dewey on Human Functioning
}

\author{
David Jaitner \\ ORCID: https://orcid.org/0000-0002-7839-9643 \\ (German Sport University Köln, d.jaitner@dshs-koeln.de)
}

\section{Introduction}

The academic strife to parse, investigate and adjust human functioning ${ }^{1}$ establishes at least three key concepts: behavior, action, activity. Considering human functioning as behavior it usually is any visible stimulus response of a human organism. Here, stimulus means any external influence that causally activates - immediately or cognitively mediated - specific modes of functioning. Reactions are all those modes of functioning activated due to specific external influences, no matter whether it is about doing or not doing something. Human functioning that is made intentionally, motive-based, and with a specific target is ideal-typical action. Here, the focus is on the realization of possibilities that are principally controlled by the human being. The human being is agens, with intentional impact on their environment to shape the future. Human functioning is not determined; it is a doing that faces environmental demands with a basically unlimited autonomy to act or refrain from a certain action, even if this factually should be limited by prevailing conditions. As activity human functioning is both active and passive. Activitytheoretical accesses retain the human possibility to shape life, but switch over from arbitrary to intrinsically determined choices. Humans are active when they no longer are universally self-determined, but still capable of shaping situations. Thus, the human being remains subject of their process of existence, however, within the scope of intrinsically and not merely secular limited degrees of freedom. Humans control their activity even in moments when something happens to them as well and when other than their mentally will is responsible.

1 Because behavior, action, activity, doing, or conduct are terminologically designated in the essay, human functioning is a neutral placeholder to designate "menschliches Tun" in a not yet terminological way. 
In the context of human functioning the chosen approach that one takes into account is therefore essential: Depending on the approach chosen, human functioning is defined in a certain way and understanding of freedom. Here, the pragmatic considerations of John Dewey (1859-1952), an American philosopher, psychologist and educational theorist, offer a sophisticatedly formulated theory of human functioning that, undoubtedly, takes action-theoretical paths but formulates underlying assumptions in a significantly unusual way. This is where the essay really begins. The aim is to outline the theory in such a way that clearly shows the unusual as part of the usual and the usual as part of the unusual. Thus, in a first section action is defined as the basic category of human functioning where sensory stimuli, registering elements, and motor responses play a leading role, but according to Dewey questions the today still popular model of behaviorist psychology, that positions isolated and a-cultural stimulus-response-procedures in the human organism. A second section affirms the theoretical inclusion of deliberative elements that constitute human action, but according to Dewey witnesses their substantial and rather sporadic significance in a predominantly habitual human functioning. A conclusive section outlines the possibilities and limits of transforming habitually inured patterns of human conduct by means of reconstructive habits.

\section{Coordinated Actions As Basic Units of Experience}

To understand or unfold philosophically based considerations, it is usually worth asking for the philosopher's fundamental project. To this, the life-long project of Dewey is a practically relevant philosophy of experience that aims to transcend all that traditional epistemological and consciousness-theoretical approaches placing humans in the world and for themselves. Dewey uses experience to denote all kinds of human to the world and reality. Man is uncircumventably in contact with the world. They factually have approach to a world that they have always been enmeshed in. This inevitably mediated relationship to the world is initially and mostly immediate (cf. primary experience). People have their world, are on the move in a universe of having, "[t]hings are objects to be treated, used, acted upon and with, enjoyed and endured" (LW 1, 28). ${ }^{2}$ Certainly, this also means that in problematic situations human beings can transition into a selfreferential form of interaction. Looking at this second level, Dewey speaks of reflexive experience, the humanly possible level of knowledge acquisition and theory formation: universally applicable from the resolution of everyday conflict situations through to academic research or philosophical reflection, and ideally carried out as inquiry, a gradual method of obtaining knowledge and thinking based on the experimental process

2 Standard references to John Dewey's work are from the critical (print) edition, The Collected Works of John Dewey, 1882-1953, edited by Jo Ann Boydston (Carbondale: Southern Illinois University Press, 1969-1991), published in three series as The Early Works (EW; 1882-1898), The Middle Works (MW; 1899-1924) and The Later Works (LW; 1925-1953). „LW 1, 28”, for example, refers to The Later Works, volume 1, page 28. 
of empirical sciences in order, in the words of Dewey's Logic. The Theory of Inquiry (1938), to transform an indeterminate situation into one "that is so determinate in its constituent distinctions and relations as to convert the elements of the original situation into a unified whole" (LW 12, 108).

In Experience and Nature (1925), Half-Hearted Naturalism (1927), or Nature in Experience (1940), Dewey calls the associated self-labeling "empirical naturalism" or "naturalistic empiricism" (LW 1, 10). Both terms are indeed laid out sui generis. In Dewey's reconstruction, naturalism relates, esp. in connection with Charles Darwin (1809-1882; e.g. MW 4, 3-14; MW 12, 114; LW 12, 97), not to an understanding of nature as "something essentially given", but "rather to an open, dynamic and contingent process in which identities and relationships emerge as the actualization of natural potentialities in the context of evolutionary interactions" (Neubert 2009, 20). Accordingly, human experience is a natural affair and is emerging from natural interactions (LW 1, 5). Empiricism, too, does not classically mean a merely subjective, passive, sensually absorbed integration of an objective world (e.g. MW 9, 276-285; MW 10, 6), but rather designates experience through the criteria of 'continuity' and 'interaction'. Both criteria are inseparable from each other, they intercept, unite and "are, so to speak, the longitudinal and lateral aspects of experience" (LW 13, 25): Experiences invariably refer to experiences, "every experience both takes up something from those which have gone before and modifies some way the quality of those which come after" (ibid., 19). Experiences are always interactions of natural events that affect human organisms, "certain modes of interaction, of correlation, of natural objects among which the organism happens, so to say, to be one" (MW 10, 26).

The elementary unit of experience is action, designed as a link between doing and undergoing wherein instrumental meanings are distilled out of existential events (e.g., EW 3, 212; MW 9, 147; MW 10, 9; LW 10, 50; LW 11, 214; LW 12, 144). Here, a theoretically consequent idea of circularity primarily manifested in an idea of a feedback of context and effect is leading the way. Action, as part of experience in nature, is always interaction between an active organism and the environment that continuously opposes the organism. In a changing and adaptable world these interactions are by no means attributable to one-dimensional effective directions and simple causal attributions, but are characterized by mutual change and adaptation. An individual person takes up selected environmental stimuli, and responds to both his environment and himself by his action addressed to the environment, thus changing the starting conditions for any further action. One cannot go twice in the same river. As part of experience in nature, action is simultaneously characterized by continuity. Interactions are far from being isolated events, but always parts of a wide stream of experiences. Interactions between humanity and environment are inevitably embedded into a context of various adaptation and change processes. There are no definite beginnings and origins. Every effect is, at the same time, cause - and vice versa. 
From the very beginning Dewey's work has been guided by this circular train of thought, and continuously differentiates itself concurrently to his theory of experience. Man is the "live creature" (LW 10, 9) that, on the one hand, is like any other living organism in nature and on the other, is the most complex organism, since humans are the self-conscious and socially living organisms in nature (cf. MW 14, 200; LW 1, 194-209; LW 3, 41-54; LW 12, 48-65).

\section{Biological Interactions of Organisms and Environments}

First, biological interactions of organisms and environments expressively dominate in Dewey's writings. The basis of that approach can already be found in The Theory of Emotions (1894), formative and highly respected to the present is the argumentation in The Reflex Arc Concept in Psychology (1896). The essay, first published in Psychological Review, identifies the criticism of a specific stimulus-response model, but does not criticize the idea of stimulus and response as such. Thus, Dewey agrees and disagrees with the empirically oriented physiological psychology developing at that time: To distance from the established introspective focus of psychology, Dewey starts with behaviorist approaches with an organic construction of human functioning, but dissociates himself clearly from its far too reductionist designing. Because of the fact that, according to Dewey, behaviorist approaches estimate the reflex arc as basic unit of psychological analysis ${ }^{3}$ and reduce human functioning to the objective observation of peripheral processes, humans are passive recipients of external impulses, and there is no inner relationship between the sensory and motor unit. The behaviorist contribution to the search for a standardized psychological research variable simply helps neither overcome the traditional separation of sensual perception, thinking and action, nor does justice to the reality of human nature: As a passive agent, humans are arbitrarily stimulated externally to initiate response. Sensory stimulus, central processing and motor responses continue to be isolated and incoherent existences, whose coordination further on can best be explained with transcendental mediating authorities or external pressures from the environment. Thus, the old dualism of body and mind is simply dressed in new clothes (EW 5, 96-99; cf. EW 2, 11-15; MW 9, 150).

3 The reflex arc denotes a physiological control loop model to explain the path followed by nerve impulses to produce reflex actions. The model is based on a mechanical input-output scheme: A stimulus impulse originates in a peripheral receptor, passes through an afferent nerve to the reflex center in the brain or spinal cord, and then out through an efferent nerve to an effector organ, where the appropriate motor response occurs. Around 1900, the model was willingly adapted by the emerging experimental psychology to establish a scientifically oriented ,exact' academic psychology (cf. Watson 1913).

4 This criticism makes Dewey appositely sensing the consequences and pitfalls of the behaviorist stimulus-response model at a very early stage of development (cf. Rorty, 1979, 228; for further critical reflections see MW 10, 53-63; MW 11, 10-17; LW 3, 45; LW 6, 27; LW 14, 185), but does not at all remain a lone voice in the wilderness. Further critical reflections to the reflex arc model are particularly found in Kurt Goldstein whose work on brain-injured First World War soldiers 
To cope with these dilemmata, Dewey psychologically takes the physiological unity of coordinated action seriously that takes the neural circuitry of the reflex arc as a basis, and integrates the reflex arc into an organic circle of functional coordination of interactions. For Dewey, life is homeostasis, an active effort to preserve or recover the equilibrium that is indispensable for the maintenance and function of an organism or organ. Thus, right on the basis of being alive, the human organism is out to shape its life at least life-sustaining (ibid., 104; cf. MW 2, 290; MW 6, 437-440; MW 10, 7ff.; LW 7, 289). Hence, the unifying principle in psychology is to be coordinated action and the basic units of human functioning are to be sensory-motor coordinations. Stimulus, cerebral activity and response are collaboratively integrated components of a single, functional unity of coordinated human action. This has two important consequences. First, context matters: The human organism has always been in contexts where it perceives a few of a multitude of sensations, then selects and interprets some of them, responding actively. A sensory stimulus not and never comes into contact with an organism unconditionally. A motor response to a stimulus is not and never universally programmed. Stimulus and response are always a result that has been and has to be constructed of all those interactions the human organism had been involved in to date. Second, stimulus and response are phases of a holistic entity: Thus, sensations and movements relate to each other in integrated action patterns, where they receive their functional form and importance, and can exclusively be explained meaningfully. Whether one, e.g., answers a loud bang with a weary smile, prying anticipation, paralyzing fear, ordered retreat, or panic-stricken flight depends, on the one hand, inevitably on the respective context of acting where the acoustic event takes place, and on the other, the respective acquired and currently available coordination patterns. The motion in action always constitutes the sensation, and the sensation in action defines the motion. Only through flight does an acoustic stimulus change into a threatening one. Only the act of hearing makes a gunshot on a dark night perceptible and motor-relevant.

concludes, inter alia, that there are no isolated stimulus-response processes in an organism, but that always the whole organism reacts (cf. 1934, 45ff.). Jean Piaget, too, vehemently underlines the unity of movement and perception, but like Goldstein does not attribute it to Dewey, but to Viktor von Weizsäcker's „Gestaltkreis” (cf. 1947, 99; 1970, 86). Karl Lashley notably questions the application of the reflex arc to complex human behaviors from a neuropsychological point of view (1951; cf. Rosenbaum, Cohen, Jax, Weiss, \& van der Wel 2007). A rather popular philosophic contradiction to the underlying relationship of cause and effect is to be found in Alan Watts example of an observer watching a line of passing cats through a narrow slit in a fence: Because the observer always sees the heads first and the tails last, and there are never tails without heads, he reasons that the event, head' is the invariable and necessary cause of the event,tail', which is the head's effect. From such a perspective, it is simply impossible to see that head and tail go together, are parts of the event ,cat' (cf. 1966, 30f.). Current efforts, references, and resumptions to Dewey's integration of perception and action in a unifying framework can be found e.g. in James Gibson's ecological approach to visual perception (1979; cf. Burke 1994, 83-96), Bernhard Hommel's „Theory of Event Coding” (cf. Hommel, Müsseler, Aschersleben, \& Prinz 2001) or in functional-dynamic alternatives in closed loop neurophysiology (cf. Wallach, Marom, \& Ahissar 2016). 
The fact that stimulus and responses are merely set as "distinctions of function, or part played, with reference to reaching or maintaining an end" (EW 5, 104; cf. MW 7, 346), i.e., as teleological distinctions without independent existential nature, questions whether these can be distinguished at all in the complex tangle of integrated action. For Dewey, the answer is clear. The distinction of stimulus as stimulus and response as response remains recognizable, but is connected to particular conditions. As long as coordination of actions is fully developed and not affected by any external disturbance, the distinction is impossible and pointless. However, if existing coordination of actions are temporarily disturbed, their flow inhibited and procedures confused, the distinction becomes psychologically effective and functional. Whenever this is the case, the outer scenery as well as the modalities of one's own action are uncertain and the restitution of coordination of action is required. Then, the broken organic circle needs to be closed in such a way that the relation of the uncertain outside and inside world can be examined and modified into a preferable, vitally suitable sensorimotor coordination (EW 5, 104109; cf. Mead 1903).

\section{Cultural Interactions of Social Individuals and Habitats}

Subsequently, Dewey increasingly focuses on cultural interactions of social individuals and habitats without, however, denying or depreciating the biological ideas of human functioning in any matter. Along with a continually matured theory of experience that, piece by piece, is fundamentally extended by social and cultural levels of meaning, an extended framework develops towards designing and measuring human functionality. The early conception of action as an organic circuit is supplemented by social and cultural contexts. In summary, this extension becomes visible in Conduct and Experience (1930). The essay, first published in the anthology Psychologies of 1930, in a first part very clearly iterates and reinforces the reconstruction of the behavioristic interpretation of the reflex arc and provides, in contrast, an integrated and circular model of human functioning. Thus, it remains clear that human functioning, or conduct - Dewey's proposed conceptual alternative for behavior - is never a mere sequence of independent and universal segments. Furthermore, it is a fatal self-misunderstanding of behaviorist psychology to believe that they move over neutral ground with their experimental-statistical methods and conduct research impartially. Indeed, the opposite is true. According to Dewey, all parts of action are functions in the context of extensive sequences of action. Human functioning develops in a circular way. Observations without observers, theoretical presuppositions and empirical variables are impossible. Regarding adequate experimental designs, all that inevitably belongs to human functioning has to be captured: the serial continuity of actions within comprehensive contexts of conduct. No act can be understood from the series to which it belongs. Thus, the motifs, intentions and situations of the examined subjects as well as the activating problems, arrangements 
of apparatus and selections of conditions set by the experimenters are scientifically relevant and need to be taken into account (LW 5, 218-224; cf. MW 11, 16f.; LW 1, 34f.; LW 6, 8).

In a second part, Dewey defers the primacy of conduct and connects the previous considerations with the idea of experience, or culture in continuity with nature (LW 1, 361; cf. Rölli 2009). In other words, the serial nature of psychological occurrence and life-historical interdependence of concrete acts of conduct are to be theoretically and empirically recognized. Hence, psychology is to be the scientific exploration and account of experience. The obvious subject matter of psychology is to be "the life-career of individualized activities" (LW 5, 224; cf. Hughes 1928). This makes the integration of mental issues mandatory. Given that sensation, perception, consciousness, reflection, or emotion, etc. are relevant in human conduct, a nonreductive empirical psychology has to include them. This means, the categories of the formerly rejected introspective foil have to be empirically revived, and at the same time the pitfalls of the declined empirical behaviorist approach are to be overcome. The given answer to the question of an appropriate relation between conduct and experience is - regarding the underlying interpretation of experience as doublebarreled word (cf. LW 1, 17f.) - hardly surprising:

The envisioned psychology receives its feedstock, mission and avenue in commonly essential distinctions of a plethora of qualities of everyday experience. These are by no means academic inventions, but emerged in real-life processes of social interactions. Sensing, perceiving, imagining, thinking, judging, reasoning, loving, or admiring, etc. are serving functions of human life that are evolutionarily established decision support in day to day pressure of constantly having to deal with themselves and the world. By living their life, humans acquire culture-specifically prestructured modes of experiencing and learn how to distinguish and behaviorally use them. These qualities of experience are not already psychology but - like, e.g., the given differences between oil and water, or iron and tin in physics and chemistry given categories of common sense that have factually to be recognized. With these the psychological science, according to Dewey's understanding of inquiry, has to start and to end as well. Hence, the science of experience psychology is located in the space between practical entrance and exit. In that context, it is psychologically quite clear and thus less interesting what acts of conduct human beings experience, and at a fundamental disposal, how human beings experience these acts of conduct. The aim of psychological studies is to provide access to all those attitudes, preferences, sensitivities, habits and techniques that can be observed when dealing with selected experiences.

In the melting pot of experiences conscious and mental forms of acting play a significant and in a certain way momentous role for human life and daily routine. It has an essentially different effect if human functioning takes place physical, physiological, 
or conscious and mental resp. what kind and level of mental activity are involved in its emergence. In acts of consciousness and mind logic, rationality, meaning, symbolic interaction, and communal participation become possible, existences and essences can be bridged, and a reciprocal nexus of means and ends to attain consequences that solve accrued problems can be achieved (e.g., MW 8, 37; LW 1, 133; LW 8, 233; LW 12, 17). With regard to research methodology, that is also slightly surprising when looking at the collective works, Dewey clearly subordinates psychological examination of this inner surface of human conduct to the scientific pattern of inquiry. Even though modes of experiencing in their immediate quality are, to a certain extent, phenomenologically explorable, for Dewey it is the direct observation of the outer surface of individual modes of experiencing which makes psychological research more objectifiable and qualifies it as genuine science (LW 5, 224-235).

\section{Positioning of the Deliberative Moment}

Even though in the previous considerations aspects of willing, thinking, reflecting, reasoning, judging, or deliberating repeatedly appear, their concrete position in Dewey's theory of human functioning as action is still not yet systematically defined. Dewey comprehensively discusses this issue by giving a systematic presentation in Human Nature and Conduct (1922). The focus of the three lectures, delivered at Leland Stanford Jr. University in May of 1918, is the search for the real foundation of human physiology and psychology (MW 14, 6; cf. LW 6, 29-39). Here, an action-theoretical argumentation is the leading concept that converts a consciousness-philosophical approach into a theory of reconstructive habits and develops an understanding of action that firmly distances itself from any utilitarian design. In doing so the human being remains a subject without presupposing a primarily rationally acting essence. Acting is reasoned response, and thus does not arbitrarily react to activating surrounding aspects, but is not significantly conscious-driven either. Man is an interactive being that, for the most part, actively and unconsciously occupies the surrounding world. Cooperation of nature, human being and society takes place, however, the consciousness that keeps in mind that man is about to engage in something with certain consequences usually lacks. Man does not act without reasons, but generally the respective result is not one that had been the explicitly cited reason but is based on pre-reflexive practical dexterity. Thus, Dewey widely limits the classical action-theoretical access but basically maintains the paradigm. The cornerstones of his argumentation are three key concepts and their interrelationships: habit, impulse, intelligence.

\section{Habit}

According to Dewey, the major determination of human nature is located in habits: Man is „a creature of habit, not of reason nor yet of instinct” (MW 14, 88). Hence, the nature of habits is the very nature of man. The mode of habit forming is the mode of 
forming humans. Human existence and development become understandable by decoding habits. Dewey introduces the nature of habit by comparing it with different physiological functions (e.g. breathing, digesting, seeing), but also restrictively points out that the latter are involuntary, and habits necessarily acquired. Common, and the analogy legitimizing feature remains the function in coordinated action. Habits are functional for the access to the world and the interaction of an individual person and the surrounding world. Individual designates the internal aspects of interaction, the individual prerequisites and subjective possibilities. The surrounding world is all that opposes, the objective conditions of the setting, the entire non-self a human being contacts and acquires habits with, embedded in habits of habit forming (ibid., 133; LW 13, 25): „Through habits formed in intercourse with the world, we (...) in-habit the world. It becomes a home and the home is part of our every experience" (LW 10, 109).

Contrary to physical or physiological functions, however, Dewey formats habits not behavior-theoretically but culture-scientifically. Habits are meaningfully acquired in individual interrelationships of elements of human nature as well as natural and social surroundings. They are bodily rooted, culturally shaped and socially multiplied unique features of human functioning. By their habits the human species create themselves a functional long-term memory against a lifetime-related transience of cultural achievements, a form of embodied histories to continually keep up with their own present and future. Habits are the reason that with every new generation the conduct of human life does not start from scratch regarding cultural development. Habits are intergenerative, socially-transferring and developing inescapable mediators of a social group to utilize and incorporate an objectively placed setting. The mode of transfer is part of the social nature of the human being and inevitable: „It is not an ethical ,ought' that conduct should be social. It is social, whether bad or good" (MW 14, 17; cf. EW 1, 231; EW 5, 86; LW 7, 253). As a condition of participation, newborns right from the moment of their birth continually and inevitably assume the objective habits, constitutive patterns of functioning and moral orientations of their social setting that in the respective group is expressed by and manifested in customs, arrangements, morals, standards, values. The remaining result is a connection between individual and objective habits, a similar group thinking and acting, ,a common understanding like-mindedness as the sociologists say" (MW 9, 7; cf. MW 6, 413).

Up to here, the major role of habit in human functioning suggests the thought of „an inherent tendency to action and also a hold, command over” (MW 14, 21). Dewey, however, defines the intended meaning of the term with marked differentiation from and in extension to "unthinking routine” (ibid., 50): to mere remote control, programmed repetition, and behavioral response to environmental stimuli. Habits are limiting tendencies that filter and control perception, thinking, feeling, action, but can principally be changed and influenced. Habits are equipped with energy and drive for power, they are the will of man that generally takes place in acts that cannot be 
consulted but might have been questioned in the past, and - at least in the event of a problem - offers the possibility of preventing an immediate relationship of will and action (ibid., 22):

Repetition is in no sense the essence of habit. (...) The essence of habit is an acquired predisposition to ways or modes of response, not to particular acts except as, under special conditions, these express a way of behaving. Habit means special sensitiveness or accessibility to certain classes of stimuli, standing predilections and aversions, rather than bare recurrence of specific acts. It means will (ibid., 32).

Hence, the selected interpretation shows "that what can be called distinctively individual in behavior and mind is not, contrary to traditional theory, an original datum" (ibid., 60; cf. MW 10, 58; MW 12, 193; LW 2, 61; LW 11, 30), but a smorgasbord of habits that change, are changeable, and have changed in a continuous interaction of nature, human being and society. In general, Dewey anchors this impact of surroundings not sociologically, but in a naturalistically-based psychologic social psychology: as „an attempt to understand and explain how the thought, feeling and behavior of individuals are influenced by the actual, imagined, or implied presence of others" (Allport 1954, 5). The focus is on the individual, personal habits, the person's mind. The goal of the findings is not how individual or collective minds form social spaces, but rather how different groups and their overly-individual characteristics create different minds.

Impressive use of this model is shown in Interpretation of the Savage Mind (1902). The essay, first published in Psychological Review, addresses the question of how the dominant activity of a social group produces generalized mental patterns and can influence the entire lifestyle significantly and the course of the human species over the long term. In terms of social theory and research method, he orients his argumentation on the demands and conditions of practice: the „mind”, as an actionguiding organ, „is at least an organ of service for the control of environment in relation to the ends of the life process" (MW 2, 41). Relevant goals are not set by pure reason, but rather through the existing tasks in daily life, through that which is done and will be done in a group in order to fundamentally shape life. Each analysis of social groups finds action-guiding patterns of thought and solely in and through the analysis of the dominant activity. A person is what he does and, to a certain extent, also conditioned by socialization processes, what he did for generations: „Occupations determine the fundamental modes of activity, and hence control the formation and use of habits" (ibid., 42, cf. LW 2, 263). Dewey exemplifies this line of argumentation on human developmental in nomadic hunting, but allows for a generalizing and perpetual significance. Characteristic for hunting, as the primary food-obtaining form of life, is its immediacy, the direct relationship between needs, activity and satisfaction of needs, of effort and reward: „Want, effort, skill and satisfaction stand in the closest relations to one another. The ultimate aim and the urgent concern of the moment 
are identical" (MW 2, 44). These statements are illustrated ethnographically in an example of Australian aborigines who demonstrate the epochal significance of hunting, the fact and the way that habits form mental patterns, those mental patterns define the important areas of life, and those mental patterns historically, at least partially and in new forms, are passed down through generations. The life of aborigines is so fundamentally defined by hunting that not only the act of hunting as such prompts mental relevance, but many parts of life can only be interpreted against this backdrop. Irrespective of whether it is art, religious ceremonies, funeral rituals, the selection of partners or sexuality, the characteristics of the prevailing activity lead to the preference for those possibilities of cultural endowment that offer a familiar degree of correspondence. According to Dewey, sports and games continue this mentally anchored striving for immediacy in and for modernity (ibid., 45).

\section{Impulse}

Thus, the priority significance of social habits is set in detail. For Dewey, however, this cannot be the only variable to develop anthropological insights. The human being is simultaneously though not synonymously an organic existence. Man owns numerous native predispositions how to respond to surrounding events: „instinctive modes of action, based in the original connections of neurons in the central nervous system" (MW 9, 67f.; cf. MW 14, 63-116; LW 10, 64). Taking this for granted, the intended classification of the human being has to give the biological reality a meaning and define the relationship of nature and nurture without wanting to use creation images. Impulses are the non-learned origin of habits, a bundle of out-going energies: „In the first place, all conduct springs ultimately and radically out of native instincts and impulses" (EW 5, 77). Stimuli are an essential puzzle piece in genesis and transformation, development and progress of individual and social habits. However, Dewey does not place them as the formative force in human functioning, but on a temporal preliminary basis: „They are secondary and dependent” (MW 14, 65). Genetics equips the embryo with unfocused tendencies. Birth puts a baby in a social setting. The interactions with a compulsorily shared setting result in the transmission of social meanings, for a respectively different direction of similar basic configuration:

The same original fears, angers, loves and hates are hopelessly entangled in the most opposite institutions. The thing we need to know is how a native stock has been modified by interaction with different environments" (ibid., 67).

Humans are born undetermined, but determinable. The undirected character of the natural constitution provides every new and existing generation with an opportunity to arbitrarily spawn certain orientations. The importance of stimuli within the theory of human functioning culminates in the fact that habits exist, that these can change in interaction with settings, and that change can happen even if what 
exists is extremely powerful. Social change is innate as well. Stimuli are the organic foundation for progress, "agencies of deviation, for giving new directions to old habits and changing their quality" (ibid.). However, due to the fact that human functioning is primarily limited by surrounding conditions, a change of habits can only be realized by the conversion of those social spaces that shape, align, adjust, or change meanings of stimuli.

Thus, the relationship of impulse and habit provides a roadmap for social improvement in a desirable, that is, according to Dewey, always democratic manner (cf. Westbrook 1991, 366): the orientation towards growth and the chance to develop, implement, and examine solutions for an intelligent experimental reorganization of habits. Growth needs flexible instead of rigid habits and often expects these as well. The point is to release impulses in such a way and by following an intelligent ideal that they can serve as starting points for particular habits. Here, the ambition is reflexive habits instead of a firm idea: Habits that empower a person to sense existing habits in the event of a problem and to reorganize them. Docility of man shall not be interpreted as encouragement to imitate, but as "power to re-make old habits" (MW 14, 70). Dewey grounds the appropriate way on two fundamental criteria: the impact on the virginity of the upcoming generation, since in childhood and youth there still exist numerous untouched stimuli that can be limited in a democratically intended manner, and transformation of existing habits due to inconsistencies. Habits interactively respond to each other, the more rigid the more friction-prone. Whenever diverging impacts meet, there is the chance to productively work on irritations in a joint solution process. Nevertheless, conflicts between social areas, classes, groups, attitudes do not arise spontaneously but need a trigger: the impulsivity.

\section{Intelligence}

Human nature and human functioning are socially limited and organically predisposed, though not programmed, but can generally also be changed and influenced. A third constituent is needed to redesign or change habits. Habit and stimulus provide an essential social and physiological basis, but it is the contribution of reason, or intelligence to find ways out and productively give events a direction:

Impulse is needed to arouse thought, incite reflection and enliven belief. But only thought notes obstructions, invents tools, conceives aims, directs technique, and thus converts impulse into an art which lives in objects. Thought is born as the twin of impulse in every moment of impeded habit. But unless it is nurtured, it speedily dies, and habit and instinct continue their civil warfare (ibid., 118).

Usually, humans identify their surrounding world in incorporated patterns of the habitual. Knowledge is knowing how, a habit that manages the life in and with the world, a practical way of thinking that does not consciously remind, or perceive 
without pausing to think, remember, observe. Only irritations of habits are a possible trigger to consciously processing solutions, and to think in a traditional pure way: "habits are not wholly informed by reasoned purpose and deliberate choice - far from it - but they are more or less amenable to them" (LW 2, 240). For such a conscious search a certain linking of habit and impulse is necessary. Driven by impulses, a particular unknown inside the well-known needs to be uncovered in such a way that well-structured and integrated conduct is achievable again. The expected mode set is experimental inquiry, a common structure of the process of non-random problem solving: Inquiry is a modification tool for existing forms of conduct by reflection of problematic situations of primary experience. The aim is to learn from consequences, and to control and prevent consequences, and better assess them. Dewey outlines the associated way of finding, working on and resolving a problem as a generalized process of a piecemeal hermeneutical adjustment. In a schematic order the human totality thereby is equally involved and needed. Thus, thinking is - according to Dewey - never "the armchair thing it is often supposed to be" (MW 10, 328), an activity exclusively taking place in the human mind's cerebral black box, but is constituted as an iterative procedure of head, heart and hands (e.g., EW 3, 83-89; MW 4, 82-90; MW 6, 188-192; MW 9, 157f.; MW 13, 61-71; LW 8, 196-209; LW 12, 105-122). In this context, impulses are the elements that push the irritation forward towards a solution. For an experimental solution, however, it is necessary that old habits join in to fill the progressing impulse with content. The impulse is triggered by conflicts, but cannot give itself a direction; it needs help from existing habits to generate new habits. The effect becomes visible in practice, by better or worse solutions of a problem. Knowing how can become, imparted by the experimental method, knowing that: "knowledge of and about things, knowledge that things are thus and so, knowledge that involves reflection and conscious appreciation" (MW 14, 125).

This means that habits are more than just a determination of thinking - but they are and continuously generate habits. There is an available creativity inherent in the nature of intelligence, a moment of intellectual stimulated transition. However, the concept of how to theoretically understand this intelligent creativity radically changes within Dewey's works. The incipient discussion about the idea can prominently be found in Psychology (1887). There, habit is "a conception of ideas or acts that, if one be presented, the rest of the series follow without the intervention of consciousness or the will" (EW 2, 100; cf. LW 17, 298-309), a cohesive system that needs an external authority to realize change and adaptation. Habit and thinking - although presumably not equally balanced - coexist, exist independently or necessarily together. In Human Nature and Conduct Dewey adjusts this separation fundamentally. Habit is no longer blind automatism, static routine, but predisposition: "It means will" (MW 14, 32). All that had initially been rooted as pure reason, is being unmasked an incorporated practice of thinking in action, as practical reason. Thinking happens as habits of 
thinking, not as soul, mind or any other autonomously-controlled retrievable dimension of reason. There is no independent organ of knowledge that motivates thinking, but knowing happens in the interaction of organism and the surrounding world and requires a certain experiential something to refer to. Reflection itself is a natural event and can be found in nature because of its own characteristics and those of nature (cf. LW 1, 80). All thinking is conditioned and always happens within the possibilities of existing habits and usual manners because, otherwise, it would be disoriented and without any changing solution: "Habit does not preclude the use of thought, but it determines the channels within it operates. Thinking is secreted in the interstices of habits" (LW 2, 335).

By this, it is consistent to democratically turn away from arbitrary thinking habits. For Dewey, the preferred method of choice is inquiry, the reflexive gradual approach from practice to the practice. Inquiry acts as an instrument for growth for the problem-based modification of arbitrary habits to specific thinking habits, accompanied by the epistemic benefit to learn from the consequences, and anticipate, control and better assess further consequences, and - as highly desired side effect - to be able to think to learn: "Still more important is the fact that the human being acquires a habit of learning. He learns to learn" (MW 9, 50). For and by a democratic experimentation community, exactly this process of singular phases of reflection needs to be transferred in an intelligent and intelligence perpetuating habit of creativity, a problem-based feature of thinking to focus results of actions in a certain way, a habitus of reflexivity: "What is necessary is that habits be formed which are more intelligent, more sensitively percipient, more with foresight, more aware what they are about, more direct and sincere, more flexibly responsive than those now current" (MW 14, 90).

\section{Communication}

Hence, the argumentation in Human Nature and Conduct is variously shaped and seems to be watertight: The human being is a creature of habit that right from the moment of their birth enter a wide and complex space of social habits that inevitably becomes the core of their nature as a social being. The development of individual habits is socially transmitted acquisition of meaning. Right from the start the human being is introduced into an established canon of fixed gateways to the world that are accessible and functionally proven in their social environment (cf. MW 1,69). Any human being is thus provided with a particular smorgasbord of habits, his or her character. In that process, the individual habits are not right next to each other, but instead penetrate one another and ensure a continuous and mixed mutual change of habits (MW 9, 30). The dependence of habits on an agile and changeable surrounding world leads in cases of inappropriate pattern of interaction to the possibility of development and change of well-established habits, and consequently of the character. Indeed, the aspiration of argumentation to plausibly open up the human genesis remains in this state. The individual character, or identity, is somehow determined from the outside to the inside intransparently as implicit imitation 
of a cultural repertoire, as imitating repetition of exemplified patterns of functioning, and is, in this rendition, provided with critical requirements by George Herbert Mead (18631931) shortly after publication:

The implications of social psychology in this book are found in the treatment of the material under three heads, that of custom and habit, that of impulse and change, and that of deliberation. Under the first he shows how inevitably these habits and customs are social, how the child enters into a vast complex of habits, and how these become the very structure of his nature as a social individual. The psychological account of the child's acquiring these habits is sketchy and inadequate. Mr. Dewey has fallen back too much upon the outworn doctrine of imitation, and for this reason he has no satisfactory account of the arising of the self in conduct. I am confident that the psychology of this is to be found first in the little child's assuming the roles of others in his continual play, and thus taking over their habits, and addressing himself as an other, in other words acquiring what is commonly called self-consciousness (Cook 1994, 378).

Approaches towards an advanced argumentation are to be found in Dewey's work as of Experience and Nature - here, however, in an implicit referential context and without any evidence for apparent borrowings from socio-psychological ideas of Mead. In the chapter "Nature, Communication and Meaning" (LW 1, 132-161) Dewey reveals his communication-theoretical essentials, the communicative meaning of social interactions and their capability of contributing to the process of habit forming. To this extension, the formation of human identity is added as an indirect process. Condition of the possibility to develop human identity is communication, as anthropological unique feature primarily, but not completely in an organized linguistic form: "Meanings run in channels formed by instrumentalities of which, in the end, language, the vehicle of thought as well as of communication is the most important" (LW 2, 210).

The development and meaning of such a human linguistic form, for Dewey, is a "story of the use" (LW 1,139): Right at the start, vocals and sounds had not predominantly been expressive and meaningful, but unconscious, unintentional, useful by and by depending on consequences: differently perceptible physical events that always then became functional when they created useful reactions in a fellow human being. The initial crying of every newborn, for example, is unplanned, but appropriate because of the generated reactions of care, attention, or affection. The transition to organized language happened by symbolically filling of acoustic signals, "used within a context of mutual assistance and direction" (ibid.), when an event can be followed by a distant, reasonably objectified consideration of what has been said. Then, and only then, sounds became words, incidental usabilities in and from the nature were repeatably preserved (e.g. fireplaces, load capacity, leverage), humans can realize meanings of sounds and react to disclosed meanings of stimuli.

Human socialization is, according to Dewey, a natural organic connection, arbitrarily identical to atoms, physical masses, plants or animals. Thus, participating in human language does not only mean that - even for a lonely hermit, a stranded castaway or in an inner monologue - at least two parties are needed; but also that, by and by, an automated 
level of reflection is installed which reveals the participation in symbolic calls to action to the human being, and that by the interpretable meaning of calls to action one's reaction can respectively be intentionally verified. Typically human is not only the view of being in a situation of interaction, but how and with what intention and expected consequences. For Dewey, the particular human structure of the inevitable association and the consequences arising from these particular structures of human communitization are more important than the fact that the association exists. Language is at the same time mean and end of the creation of social coherences and coordination of action, and is functional for the process of human cooperation and participation:

Language is always a form of action and in its instrumental use is always a means of concerted action for an end, while at the time it finds in itself all the goods of its possible consequences. For there is no mode of action as fulfilling and as rewarding as is concerted consensus of action. It brings with it the sense of sharing and merging in a whole. Forms of language are unrivalled in ability to create this sense, at first with direct participation on the part of an audience (LW $1,144 \mathrm{f}$.).

Language acquisition and thus the capability of truly human interacting and being a self is always mediated by social contexts. The self only exclusively develops as meanings created by interaction processes, it is always a social self that reaches its 'I' exclusively inside a 'you', and not just a naturally existing phenomenon that somehow, somewhere, sometimes finds its expression in language: "We form our ideas, our estimates of ourselves and of our self-respect in terms of what others think of us, in terms of the way in which they treat us" (LW 5, 239). Condition of the possibility for interaction and identity is role-taking, deposited in a specific characteristic of acoustic sounds. Language is a vocal gesture and transfers the speaker - contrary to facial expressions, gesture or posture into a state of subject and object. The speaker talks and simultaneously hears, like any other person, what is being said. The possibility of being the object of one's own vocal gesture and hearing oneself without perspective enables humans to empathize with their interaction partners, initiate a retrospective to themselves, mutually anticipate reactions to their actions and compare them with real reactions, and establish - in mutual agreement and analysis of meanings - a system of significant symbols. Action becomes mutually predictable through significant symbols and can expediently be coordinated as mutual anticipation of functioning. Thoughtfully delving into the role of another person means estimating prior to an action how the opponent will react to one's functioning by reflecting on one's own functioning and reaction from the other person's perspective, provided that similar conditions of socialization and a rough intersection of significant symbols are given. Only via a differentiated language system does it become possible to creatively assume different roles and outline oneself in the looks of the interactive others. Thus, the mutual anticipation of the expectation of an interaction partner is not only condition for successful interaction, but at the same time prerequisite for a unique identity and for a subject that, additionally, does not limit itself in the imitation of habits 
from an objective viewers perspective, but - of course, still without exit from the bias in "habits of speech" (LW 1, 145) - adds socially agreed-upon meanings to events and acquires habits.

\section{Conclusion}

The collected works of Dewey are characterized in that the anti-skeptical fallibilism that he epistemologically stands up for does not stop at his own thinking. Initiated by sometimes more valid arguments, sometimes recent scientific data, commonly experiences, or personal relationships, smaller or larger upheavals continuously can be traced. Sometimes, these turn the previous thoughts upside down (cf. LW 5, 147-160), and sometimes 'just' an extension or reweighting of positions happens. The aim of this essay was to outline Dewey's theory of human functioning. The result is a construct that, from the beginning, formulates basic characteristics but that, little by little, extends and reshapes design and weighting. The basic structure is of permanent nature: experience is and remains the basic benchmark. The basic trait is to be alive and, as a living creature, to interactively create a balance to sustain and push life forward. The basic unit is and remains unified action. The basic principle is and remains a specific idea of circularity. The basic mission of academic study is and remains to take the context and continuity of human conduct empirically seriously. In particular, the substantive content undergoes modification: Sustainably influenced by William James' The Principles of Psychology (1890) at the beginning the idea of an active biological organism to be studied through the methods of physiological psychology is in focus. Human functioning is the biological interaction of organism and environment and primarily takes place via sensori-motor functions and coordination. Later, especially in the socio-psychological exchange with George Herbert Mead, social patterns of conduct and meaningful series of action rather predominate without giving away the naturalistic perspective in any manner. The organism is amplified by the social individual, environments with habitats, and organic contexts by cultural ones.

The connector that integrates this extension into the idea of circularity is the concept of habit. ${ }^{5}$ For Dewey, habits are inured structures of conduct, customary values, traditions and institutions that combine social functions and elements of personality. There is a double meaning inherent in the concept. On the one hand, habits are the enormous flywheel of human life, its most precious conservative facilitator: Habits, "overlaid and saturated with the products of the reflection of past generations and bygone ages" (LW 1,40 ), have a stabilizing effect and are - for particular cultural groups - predictable regarding the respective daily and smooth functional process of individual and habitat.

5 In American pragmatism the steering towards exactly that concept is traditional (cf. MacMullan 2013). Early discussions that Dewey certainly knew about are to be found in Charles Sanders Peirce $(1877,5)$, or William James $(1890,121$ f.). For further examinations see, e.g., Brinkmann (2011), Cutchin (2007), Garrison (2002), Koschmann (2000), Pratten (2015), or Schäfer (2012). 
Habits "possess us, rather than we them, [t]hey move us, they control us" (MW 9, 34). For the most part, the individual and collective life works because it takes place in a culturally specific learned manner, unchallenged (cf. LW 1, 22f.). On the other hand, this functionality bears the risk of restricted cultural reproduction: of routine, dissatisfying stagnation, "dead habits" (MW 14, 51). Life is taking place on socially predefined paths. One stews in his or her own juice. Demands and uncertainties are worked on according to existing patterns, the more solidified the less consciously (LW 1, 235). Change and innovation are only possible in problematic situations and with help of a biological basis. Whenever an organic individual falls out of step with the march of its surrounding, there is the possibility and urgency to recover unison with it (LW 10,19). Now, this return to pre-problematic equilibria can occur happenstance or via directed effort. The most controlling, hence the instrument of choice to be inevitably preferred - and en passant the bridge to Dewey's educational and political implications of habits (cf. Campbell 1998) - is experimental inquiry.

Experimental thinking enables humans to overcome their thinking, feeling and action caught up in habits in a hitherto best possible way. According to Dewey, experimental adjustment is the human ability to maintain all those habits from retrospective experiences that are prospectively useful in actively and expediently shaping the environment and habitat for individual and collective purposes, and the ability to extract those patterns of conduct from these experiences that offer - regardless of the extent of its previous usefulness - suboptimal and vacant solutions for topical problems and irritations. Experimental thinking is the way of adjustment by use of reconstructive non-conformism, and is the instrument to work on biological and cultural limitations as well as to achieve freedom and individuality. And, in this context, freedom and individuality do not mean solitude and riddance of environment and habitat, but the practical knowledge of their mechanism, and (as extensively as possible) shaped reconstructive habits of reflective thinking and intelligent action:

Experience is not a rigid and closed thing; it is vital, and hence growing. When dominated by the past, by custom and routine, it is often opposed to the reasonable, the thoughtful. But experience also includes the reflection that sets us free from the limiting influence of sense, appetite, and tradition (LW 8, 277).

\section{References}

Allport G. W. 1954. „The Historical Background of Modern Social Psychology“, in G. Lindzey (Ed.), Handbook of Social Psychology. Reading: Addison-Wesley (3-56). Brinkmann S. 2011. „Dewey’s Neglected Psychology: Rediscovering His Transactional Approach." Theory \& Psychology 21:298-317. 
Burke T. 1994. Dewey's New Logic: A Reply to Russell. Chicago: University of Chicago Press.

Campbell J. 1998. „Dewey's Conception of Community,” in L. A. Hickman (Ed.), Reading Dewey. Interpretations for a Postmodern Generation. Bloomington: Indiana University Press (23-42).

Cook G. A. 1994. „George Herbert Mead: An Unpublished Review of John Dewey’s Human Nature and Conduct." Journal of the History of the Behavioral Sciences 30:374-79.

Cutchin M. P. 2007. „From Society to Self (and Back) Through Place: Habit in Transactional Context." OTJR: Occupation, Participation and Health 27:50S-59S.

Dewey J. EW 1-5. The Early Works: 1882-1898, edited by J. A. Boydston [1969-1975]. Carbondale: Southern Illinois University Press.

Dewey J. MW 1-15. The Middle Works: 1899-1924, edited by J. A. Boydston [1976-1983]. Carbondale: Southern Illinois University Press.

Dewey J. LW 1-17. The Later Works: 1925-1953, edited by J. A. Boydston [1981-2001]. Carbondale: Southern Illinois University Press.

Garrison J. W. 2002. „Habit as Social Tools in Context.“ OTJR: Occupation, Participation and Health 22:11S-17S.

Gibson J. J. 1979. The Ecological Approach to Visual Perception. Boston: Houghton Mifflin.

Goldstein K. 1934. Der Aufbau des Organismus: Einführung in die Biologie unter besonderer Berücksichtigung der Erfahrungen am kranken Menschen. The Hague: Martinus Nijhoff.

Hommel B., Müsseler J., Aschersleben G., \& Prinz W. 2001. „The Theory of Event Coding (TEC): A Framework for Perception and Action Planning." Behavioral and Brain Sciences 24:849-937.

Hughes P. 1928. An Introduction to Psychology: From the Standpoint of Life-career. Bethlehem: Lehigh University Supply Bureau.

James W. 1890. The Principles in Psychology. New York: Dover.

Koschmann T. 2000. „The Physiological and the Social in the Psychologies of Dewey and Thorndike: The Matter of Habit," in B. Fishman \& S. O'Connor-Divelbiss (Eds.), Facing the Challenges of Complex Real-World Settings. Mahwah: Erlbaum (314-19).

Lashley K. S. 1951. „The Problem of Serial Order in Behavior,“ in L. A. Jeffress (Ed.), Cerebral Mechanisms in Behavior. New York: John Wiley and Sons (112-36).

MacMullan T. 2013. „The Fly Wheel of Society: Habit and Social Meliorism in the Pragmatist Tradition," in T. Sparrow \& A. Hutchinson (Eds.), A History of Habit: from Aristotle to Bourdieu. Lanham: Lexington Books (229-55).

Mead G. H. 1903. „The Definition of the Psychical.“ Decennial Publications of the University of Chicago 3:77-112. 
Neubert S. 2009. „Pragmatism: Diversity of Subjects in Dewey's Philosophy and the Present Dewey Scholarship," in L. A. Hickmann, S. Neubert, \& K. Reich (Eds.), John Dewey Between Pragmatism and Constructivism. New York: Fordham University Press (19-38).

Peirce C. S. 1877. „The Fixation of Belief.“ Popular Science Monthly 12:1-15.

Piaget J. 1970. Abriß der genetischen Epistemologie (German ed. 1974, trans. by F. Kubli). Freiburg: Walter.

Piaget J. 1947. Psychologie der Intelligenz (German ed. 1976, trans. by H. Aebli). München: Kindler.

Pratten S. 2015. „Dewey on Habit, Character, Order and Reform.“ Cambridge Journal of Economics 39:1031-52.

Rölli M. 2009. „Natur und Kultur. Oder: Wie der Pragmatismus John Deweys einen traditionsreichen Gegensatz aufhebt". Allgemeine Zeitschrift für Philosophie 34:305-29.

Rorty R. 1979. Philosophy and the Mirror of Nature. Princeton: Princeton University Press.

Rosenbaum D. A., Cohen R. G., Jax S. A., Weiss D. J., \& van der Wel R. 2007. „The Problem of Serial Order in Behavior: Lashley's Legacy." Human Movement Science 26:525-54.

Schäfer H. 2012. „Kreativität und Gewohnheit. Ein Vergleich zwischen Praxistheorie und Pragmatismus", in U. Göttlich \& R. Kurt (Hg.), Kreativität und Improvisation. Soziologische Positionen. Wiesbaden: Springer Fachmedien (17-44).

Wallach A., Marom S., \& Ahissar E. 2016. „Closing Dewey’s Circuit,“ in A. El Hady (Ed.), Closed Loop Neuroscience. London: Elsevier Science (93-100).

Watson J. B. 1913. „Psychology As the Behaviorist Views It.“ Psychological Review 20:158-77.

Watts A. 1966. The Book. The Taboo Against Knowing Who You Are. New York: Pantheon. Westbrook R. B. 1991. John Dewey and American Democracy. Ithaca: Cornell University Press. 


\title{
David Jaitner
}

(Köln)

Reconstructive Habits: John Dewey on Human Functioning

\begin{abstract}
The academic strife to parse, investigate and adjust human functioning establishes varieties of at least three key concepts: behavior, action, activity. Depending on the general approach chosen, human functioning is therefore defined in a certain way and in a certain understanding of freedom. Within this paper, the pragmatist considerations of John Dewey (1859-1952) offer a sophisticatedly formulated theory of human functioning that, undoubtedly, takes action-theoretical paths but formulates underlying assumptions in a significantly unusual way. The main focus is to outline the theory in such a way that clearly shows the unusual as part of the usual and the usual as part of the unusual. For this purpose, the first section defines action as the basic category of Deweyan human functioning where sensory stimuli, registering elements and motor responses play a leading role, but according to Dewey questions the today still popular model of behaviorist psychology, that positions isolated and a-cultural stimulus-responseprocedures in the human organism. The second section affirms the theoretical inclusion of deliberative elements that constitute human action, but according to Dewey witnesses their substantial and rather sporadic significance in a predominantly habitual human functioning. The conclusive section outlines the possibilities and limits of transforming habitually inured patterns of human conduct by means of reconstructive habits.
\end{abstract}

Keywords: human functioning; habit; reconstruction; pragmatism; John Dewey.

Ethics in Progress (ISSN 2084-9257). Vol. 9 (2018). No. 1, Art. \#1, pp. 4-24.

Creative Commons BY-SA 3.0

Doi: 10.14746/eip.2018.1.1 